\title{
THE RHETORIC OF THE UAE'S MIDDLE EAST CIVILIZATION ADVANCEMENT TO THE SURROUNDING NATURAL ECOSYSTEM
}

\author{
Subhan Jaelani ${ }^{1}$ \\ ${ }^{1}$ Program Studi Magister Kajian Budaya Timur Tengah \\ Departemen Antarbudaya Fakultas Ilmu Budaya \\ Universitas Gadjah Mada \\ ${ }^{1}$ subhan.jaelani@ugm.ac.id
}

\begin{abstract}
The Middle East is side by side with western countries competing in optimal utilization in processing the resources provided by the earth. Clean water is an absolute source of life that humans need. In addition, the technology and wealth of a country are the benchmarks for supporting the achievement of a country's goals. The use of manipulated nature to meet the needs of clean water is the idea of one of the developed countries in the Middle East, namely the United Arab Emirates. The United Arab Emirates, which is rich in natural wealth and abundant wealth, accompanied by advances in mindset and technology that is never separated from commemorating its culture, makes them think more deeply than other countries with their wealth of clean water. The sowing of salt in the atmosphere along with desalination/filtration of seawater into ready-to-consume water is an action taken by the Emirate to meet the needs of its people. Changes in natural ecosystems that were originally arid to become barren and green are almost impossible actions but have been successfully carried out and implemented by developed countries in the Middle East. Then the question arises about whether changing the shape and manipulating nature that should be as usual in this ecosystem will have an impact or benefit the general public.
\end{abstract}

Keywords : Civilization Advancement, Middle East, Ecosystem, Water

$$
\begin{aligned}
& \text { ملخص } \\
& \text { يقف الشرق الأوسط جنبًا إلى جنب مع الدول الغربية التي تتنافس في الاستخدام الأمثل في معالجة الموارد التي توفرها } \\
& \text { الأرض. ومن بين هذه الموارد الطبيعية الماء النظيف الذى هو مصدر مطلق للحياة يحتاجه الإنسان. وتعد التكنولوجيا }
\end{aligned}
$$

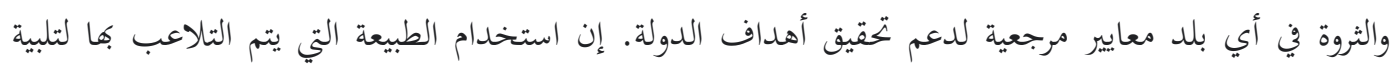

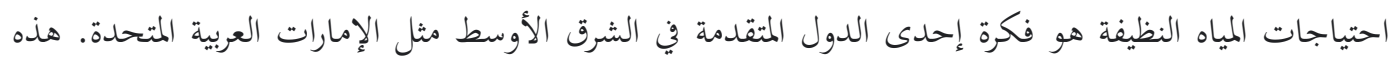

$$
\begin{aligned}
& \text { الدولة الغنية بالثروات الطبيعية والوفرة والمصحوبة بتطورات في العلوم والتكنولوجيا التى لا تنفصل أبدًا عن تراثها }
\end{aligned}
$$

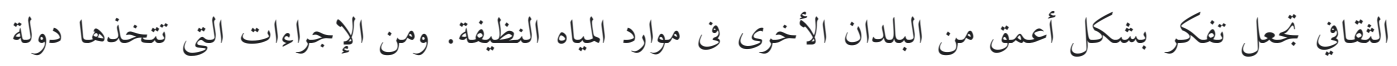

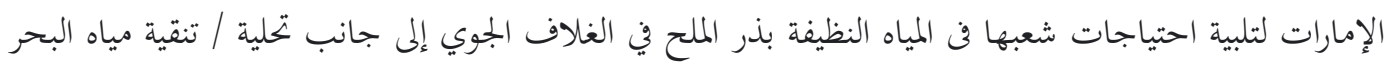

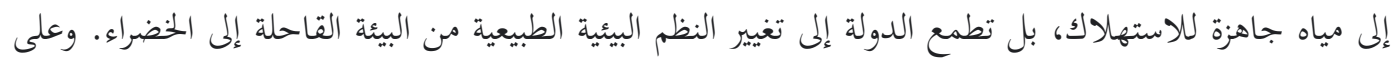

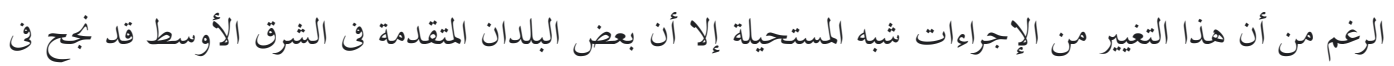

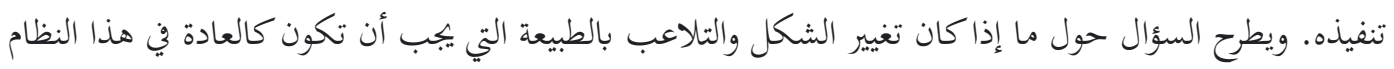

$$
\begin{aligned}
& \text { البيئي سيكون له تأثير أو فائدة لعامة الناس. } \\
& \text { الكلمات المفتاحية: تقدم الحضارة، الشرق الأوسط، النظام البيئي، المياه. }
\end{aligned}
$$




\section{A. Pendahuluan}

Hamparan daratan dan elemen air yang menguasai dua pertiga bumi terdapat di dalamnya ekosistem besar bernyawa yang terdiri dari jutaan makhuk hidup. Manusia merupakan salah satu makhluk yang bernapas dan berkembang di muka bumi. Kategori pembeda dari manusia dengan makhluk lainnya ialah tingkat kecerdasan dan pengendalian nafsu/emosi yang membuat manusia diyakini superior. Seiring berjalannya waktu, akal tersebut berkembang dan mengendalikan peradaban hingga saat ini. Perkembangan segala aspek kehidupan manusia menunjukan seberapa advance pemikiran manusia ketimbang makhluk lainnya meskipun berjalan paralel yang bersifat positif ataupun negatif. Begitu pula dengan keberadaan kepercayaan agama, yaitu agama islam yang berpopulasi penganut terbesar di dunia, diberikan pandagan bahwa manusia sebagai makhluk yang diciptakan dengan bentuk fisik yang paling sempurna (QS. At-Tīn [95]:4) dan dijadikannya khalifah di muka bumi (QS. Al-Baqarah [2]:30) yang berarti tanggung jawab manusia dengan kesempurnaan akal dan emosi/nafsu serta fisiknya terhadap keberlangsungan bumi adalah tugas yang perlu diemban.

Ribuan generasi manusia telah menempuh kehidupan hingga saat ini, begitu pula dengan ekosistem dan lingkungan di sekitarnya. Sumber daya alam yang melimpah di muka bumi ini telah dimanfaatkan pula seperti halnya manusia, terbentuk dan tumbuhnya alam mengikuti usia dari manusia yang memanfaatkannya. Kekayaan alam yang melimpah membuat kebutuhan manusia terasa selalu tidak mencukupi, sedangkan alam memiliki kapasitas ambang batas aman yang bisa dikonsumsi. Berbagai cara dari kecerdasan manusia yang diimplementasikan turut berkembang agar dapat memenuhi kebutuhan manusia untuk melangsungkan hidup dan terus berkembang bersama alam. Menurut Tortell (2020) dalam bukunya An Insider's Guide to a Rapidly Changing Planet, bahwa pada kenyataannya, manusia dengan populasi yang tidak seimbang dengan laju perkembangan dari alam, membuat alam kewalahan dalam memberikan ketersediaan kekayaannya untuk memenuhi kebutuhan manusia.

Segala bentuk cara yang menghalalkan aksi perusakan yang ilegal merajalela dilakukan oknum manusia yang ingin memperkaya diri dan kelompoknya. Keseimbangan ekosistem yang tidak terkendali dan terpantau dalam pelestariannya pun terusik. Tidak sedikit pula hal itu merusak secara terangterangan, tetapi berhasil mendapatkan izin pemerintah setempat dalam kegiatan eksploitasinya. Tingkat kebutuhan oknum yang tidak bertanggungjawab menciptakan ketidakseimbangan dan ketidakselarasan antar kaum yang sadar dan yang merusak. Segala penjuru negara mengalami hal ini dalam konteks kegiatan ilegal dalam meraup kekayaan alam.

Pada dasarnya, manusia bergerak berdasarkan keyakinannya masing-masing dalam menjalankan kehidupan. Bergeraknya pola pikir manusia tentunya menghadapi segala macam rintangan dan gesekan satu dengan lainnya membentuk kelompok-kelompok yang diyakini sepaham dan sepemikiran dalam melangsungkan kehidupan. Hal tersebut tidak luput dari sifat alamiah manusia sebagai makhluk sosial. Mulai dari keluarga, teman-teman terdekat, hingga keanggotaan di suatu perkumpulan resmi di masyarakat, semua itu adalah macammacam kelompok sosial yang terbentuk secara sengaja maupun tidak sengaja. Bergabungnya individu dalam suatu kelompok sosial merupakan keinginan dari dalam diri individu tersebut atau bahkan bisa terjadi secara kebetulan.

Sebagai makhluk sosial, kehidupan sehari-hari manusia dipenuhi oleh berbagai interaksi dengan kelompok sosial yang lain. Menurut H. Bonner (1959) dalam bukunya yang berjudul Social Psychology, interaksi sosial adalah suatu hubungan antara dua atau lebih individu manusia, yang kelakuan individu yang satu mempengaruhi, mengubah, atau memperbaiki kelakuan individu yang lain, atau sebaliknya. Rumusan ini dengan tepat 
menggambarkan kelangsungan timbalbalik interaksi sosial dua atau lebih manusia itu. Sementara itu, individu yang satu dapat menyesuaikan diri secara autoplastis kepada individu yang lain, sehingga dirinya dipengaruhi oleh diri yang lain. Individu yang satu dapat juga menyesuaikan diri secara autoplastis dengan individu lain, dan individu yang lain itulah yang dipengaruhi oleh dirinya yang pertama. Dengan demikian, hubungan antara individu yang berinteraksi senantiasa merupakan hubungan timbalbalik, saling memengaruhi.

Kelompok sosial dengan pemikiran dan prinsip yang beragam membuahkan ideologi dan juga Poleksosbud (politik, ekonomi, sosial, budaya) yang nantinya berkembang dan bertambah elemennya berupa Hankam (pertahanan dan keamanan) untuk kepentingan kelompoknya atau dalam istilah di Indonesia adalah Gatra Sosial dari Asta Gatra Nasional. Selain sosial, adapula istilah Trigatra yang merupakan Gatra Alamiah atau Natural Resources yang terdiri atas: 1) letak dan kedudukan geografis Indonesia, 2) keadaan dan juga kekayaan alam Indonesia, 3) keadaan dan kemampuan dari penduduk Indonesia. Dalam hal ini, istilah tiap negara berbeda tetapi maksud dari pengelompokkan dan simplifikasinya tidak jauh berbeda.

Kebutuhan sebuah negara atau elemen negara pun masih ambigu dalam penentuan prioritasnya. Ideologi bertebaran dengan maksud pemenuhan dan pencapaian tujuan dari negara ataupun rakyatnya. Alam menjadi sebuah sumber daya yang tidak dapat dihindari dan selalu dijadikan sumber kehidupan sebuah peradaban. Geografis yang berbeda di setiap negara menjadi penentu kemajuan peradaban, tetapi berbeda dengan kekayaan alam sebuah negara juga menjadi penentu dari peradaban tersebut. Kekayaan alam yang didukung dengan kemajuan pola pikir dan teknologi tentunya mengarahkan sebuah negara pada kemajuan, begitu pula sebaliknya apabila kekayaan alam yang melimpah tetapi tidak dimanfaatkan dengan baik oleh pengelola tanah, dalam hal ini negara, tentunya tidak akan menguntungkan pula. Seperti contoh negara kebanyakan di benua Afrika seperti Republik Demokratik Kongo yang memiliki kekayaan melimpah seperti berlian, emas, tembaga yang paling bermanfaat pada zaman teknologi peradaban maju ialah mineral Tantalum. Sangat disayangkan, manajerial yang kurang baik, dalam konteks ini pengelolaan dan kerja sama yang timpang dengan negara maju lainnya, membuat negara tersebut tidak jauh berbeda dengan negaranegara Afrika lainnya dengan tingkat kemiskinan yang tinggi bahkan menduduki peringkat 3 di dunia pada 2019.

Berbanding terbalik dengan beberapa negara Timur Tengah lainnya, Uni Emirat Arab sangat maju dalam pengelolaan kekayaan alam dan bahkan berhasil menerapkan sesuatu yang dipercaya mustahil menjadi terealisasikan. Menurut Ventura (2020) dalam artikel penilitiannya dengan judul Poorest Countries in the World 2020, Emirat Arab sebagai negara yang kaya akan kekayaan alamnya yang berupa sumber minyak mentah dan dengan pengelolaan optimal terhadap sumber alam tersebut menjadikan negara itu negara terkaya ke-2 di Timur Tengah dan menduduki peringkat 8 dunia di bawah Qatar, Makau, Luxembourg, Singapura, Irlandia, Brunei Darussalam dan Norwegia pada 2019.

Dengan segala kemampuannya tersebut, Uni Emirat Arab memanfaatkan teknologi dan implementasi pola alam yang dimanipulasi agar dapat memenuhi kebutuhan air bersih. UEA yang kaya akan kekayaan alamnya dan harta yang melimpah disertai dengan kemajuan pola pikir dan teknologi yang tidak pernah lepas dalam memperingati kebudayaannya, membuat mereka berpikir lebih dalam dari negara yang lain dengan kekayaan akan air bersihnya. Hal tersebut menjadi perhatian utama dalam penelitian ini dengan pendalaman data yang disertai pandangan peneliti lainnya terkait fenomena pemanipulasian alam ini.

\section{B. Metodologi}

Metode penelitian berisi cara kerja tersistem penelitian. Metode penelitian 
meliputi langkah-langkah kerja riil penelitian, mulai dari pengumpulan data, klasifikasi data, analisis data, sampai penyajian hasil analisis data. Metode pengumpulan data, klasifikasi data, analisis data, dan penyajian hasil analisis data disesuaikan dengan bidang keilmuan yang diteliti.

Dalam menyelesaikan penelitian ini penulis menggunakan metode kualitatif. Menurut John W. Cresswell (2009), dalam bukunya Research Design : Qualitative, Quantitative and Mixed Methods Approaches, metode penelitian kualitatif itu sendiri adalah suatu prosedur penelitian yang menghasilkan data deskriptif berupa kata-kata tertulis atau lisan dari orangorang dan perilaku yang dapat diamati, berfokus pada proses-proses yang terjadi dan khususnya berusaha memahami bagaimana sesuatu itu muncul. Permasalahan yang akan dikaji oleh peneliti merupakan masalah yang bersifat sosial dan dinamis. Oleh karena itu, peneliti memilih menggunakan metode penelitian kualitatif untuk menentukan cara mencari, mengumpulkan, mengolah dan menganalisis data hasil penelitian tersebut. Penelitian kualitatif ini dapat digunakan untuk memahami interaksi sosial.

Penelitian kualitatif menggunakan strategi penelitian yang berfokus pada penggunaan kata-kata daripada kuantifikasi dalam mencari dan menganalisis data. Menurut Alan Bryman (2012) dalam bukunya Social Research Methods, 4th Edition terdapat dua aspek penting dalam metode ini yang meliputi, interpretasi data empirik dengan teori serta penggunaan grafik sebagai acuan analisis dalam menyimpulkan temuan-temuan. Penelitian ini dimaksudkan untuk memahami fenomena tentang apa yang dialami oleh subjek penelitian secara holistik, dengan cara deskripsi dalam bentuk kata-kata bahasa, pada suatu konteks khusus yang alamiah dan dengan memanfaatkan berbagai metode ilmiah seperti halnya yang telah dibahas oleh Moleong Lexy, J (1996) dalam bukunya yang berjudul Metodologi Penelitian Kualitatif. Oleh karena itu, peneliti akan menginterpretasikan data-data dan fakta yang telah ada sebagai hasil konstruksi yang berkaitan dengan permasalahan yang diteliti untuk memperkaya perspektif dan menyesuaikannya dengan teori untuk menghasilkan analisis kualitatif yang spesifik atau akurat.

\section{Pembahasan}

Ketersediaan air bersih yang dapat dikonsumsi tidak sebanyak air laut yang menguasai planet bumi. Teknologi dan kekayaan harta sebuah negara mejadi tolak ukur pendukung dalam meraih tujuan sebuah negara. Pemanfaatan alam yang dimanipulasi agar dapat memenuhi kebutuhan air bersih menjadi ide salah satu negara maju di Timur Tengah yaitu Uni Emirat Arab. Uni Emirat Arab yang kaya akan kekayaan alamnya dan harta yang melimpah disertai dengan kemajuan pola pikir dan teknologi yang tidak pernah lepas dalam memperingati kebudayaannya, membuat mereka berpikir lebih dalam untuk mengatasi problema terkait air bersih dibandingkan negara yang lain dengan kekayaan akan air bersihnya.

\section{Sejarah Kekayaan dan Peradaban}

Uni Emirat Arab adalah salah satu dari 10 produsen minyak dan gas alam terbesar di dunia, dan merupakan anggota Organisasi Negara Pengekspor Minyak (OPEC) dan Forum Negara Pengekspor Gas (GECF). Ini adalah penghasil dan pengekspor minyak utama. Pada tahun 2012, negara ini memproduksi rata-rata 2,8 juta barel minyak mentah per hari; total tertinggi kedelapan di dunia. Uni Emirat Arab tampaknya tidak mungkin memenuhi target produksi minyak mentah 3 juta barel per hari pada akhir 2013. Lebih lanjut, negara tersebut dapat mendorong kembali target jangka panjang 3,5 juta barel per hari hingga akhir dasawarsa. UEA memiliki salah satu tingkat konsumsi minyak per kapita tertinggi di dunia. UEA berencana untuk meningkatkan produksi gas alam domestik selama beberapa tahun ke depan untuk membantu memenuhi permintaan internal yang terus meningkat. Sebagian besar pertumbuhan dapat berasal dari cadangan gas asam (sulfur tinggi) yang besar di negara itu. Sudah menjadi 20 
produsen gas alam global teratas, UEA memiliki beberapa proyek yang sedang berlangsung yang dapat meningkatkan produksi gas alam negara itu secara signifikan selama beberapa tahun ke depan. Uni Emirat Arab adalah negara pertama di Timur Tengah yang mengekspor gas alam cair (LNG), dan telah mengekspor lebih dari 250 miliar kaki kubik LNG setiap tahun, hampir secara eksklusif ke Asia. Berdasarkan penelitian dan data yang dikemukakan oleh M. Kazim (2007) adalam artikel Assessments of Primary Energy Consumption and Its Environmental Consequences in The United Arab Emirates UEA memiliki cadangan gas alam terbesar ketujuh di dunia, lebih dari 215 triliun kaki kubik (Tcf). Terlepas dari sumbangannya yang besar, UEA menjadi importir bersih gas alam pada tahun 2008 .

Meskipun memiliki cadangan hidrokarbon terbesar di dunia, UEA berencana untuk mendiversifikasi bauran energinya di luar pembangkit listrik berbasis hidrokarbon, termasuk teknologi nuklir dan energi terbarukan. Pada Desember 2009, UEA memberikan kontrak \$ 20 miliar kepada Korea Electric Power Corporation (KEPCO) untuk membangun empat reaktor nuklir, dan pada Juli 2012 lisensi disetujui untuk KEPCO untuk memulai pembangunan dua reaktor 1.400 megawatt pertama. Reaktor pertama dijadwalkan mulai beroperasi pada 2017, sementara yang lain diharapkan selesai pada 2020. Setelah selesainya reaktor pertama, UEA akan menjadi negara kedua di kawasan (setelah Iran) yang memiliki program nuklir domestik. Untuk menghindari kekhawatiran tentang penggunaan teknologi nuklir mereka, UEA meminta dan menerima persetujuan Badan Energi Atom Internasional (IAEA) untuk proyek nuklirnya, dan berkomitmen untuk tidak melakukan pengayaan dalam negeri dan pemrosesan ulang bahan bakar nuklir dengan menandatangani undang-undang yang melarang itu. Selain itu, UEA menandatangani perjanjian kerja sama nuklir dengan Amerika Serikat pada tahun 2009, dan merupakan penandatangan Perjanjian Non-Proliferasi Nuklir.
Kekayaan minyak dan kekayaan alam lainnya telah mengubah masyarakat Teluk Arab dengan cara yang cepat dan mendalam. Tidaklah mudah bagi kegiatan ekonomi tradisional yang berusia berabadabad dan berbasis subsistensi untuk menyesuaikan diri dengan ekonomi minyak baru, yang dengan cepat terintegrasi dalam ekonomi global kapitalis yang agresif. Industri ekonomi lama dan mode kehidupan material runtuh, termasuk mutiara, perikanan, perdagangan laut, pembangunan kapal, pertanian oasis skala kecil, dan pastoralisme. Dalam kasus Uni Emirat Arab pada 1960-an dan 1970-an yang sebelumnya pernah dibahas oleh Sulayman Khalaf (2000) dalam bukunya dengan judul Poetics and Politics of Newly Invented Traditions in the Gulf: Camel Racing in the United Arab Emirates, realitas sosial ekonomi baru muncul, seperti dibuktikan, misalnya, dengan menetapnya orang Badu (Badui) secara masif di desa-desa dan pusat-pusat kota baru di mana mereka sekarang menikmati berkah kekayaan dan konsumsi tinggi dengan kehidupan mewah dan tidak lepas dari pendingin ruangan.

Dalam konteks ekonomi baru ini, manfaat dan kegunaan unta sebelumnya, yang dulunya penting dalam kehidupan pastoral Badui, menghilang dengan cepat. Unta dan ekologi gurunnya diabaikan dan dipinggirkan. Dalam ekologi budaya minyak yang baru, unta yang dulunya merupakan hewan penggerak berkaki empat yang serba bisa dan serba guna digantikan oleh mesin penggerak empat roda Toyota. Pengenalan istilah "Bahtera nya Gurun Pasir" telah terhentikan dari berlayar melintasi bukit pasir dan sekarang dibawa dengan roda ke berbagai tujuan di Teluk, termasuk pacuan unta.

Di UEA, selama musim balap yang panjang dari Oktober hingga April, hejin yang ramping menjadi pusat perhatian bagi penduduk lokal dan ekspatriat. Layar televisi (yang sekarang sudah umum di mana-mana) menghadirkan olahraga tradisional ciptaan ini kepada setiap keluarga dalam kenyamanan rumah mereka sendiri. Sama pentingnya, balapan membawa orang-orang yang terlibat dalam 
industri nasional yang sedang berkembang ini tidak hanya kepuasan modal budaya, dan kehormatan sosial tetapi juga keuntungan material: pekerjaan sebagai peternak dan pelatih dan hadiah uang tunai seperti kendaraan roda empat dan mobil mewah seperti Mercedes, BMW, dan Lexus.

Menciptakan tradisi balap unta di Teluk Emirates memiliki dimensi yang kompleks dan banyak fungsi dalam konteks sejarah pasca-minyak ini. Kekayaan baru yang sangat besar, perubahan sosial yang cepat, dan runtuhnya ekonomi dan gaya hidup tradisional menantang proses pembangunan bangsa. Melestarikan pusaka dan memelihara identitas budaya dalam konteks ancaman kekuatan global merupakan dinamika penemuan tradisi dalam masyarakat kaya minyak, yang memberi makna pada wacana politikbudaya yang dimilikinya. Kegiatan pemujaan unta ras sebagai ikon budaya memberikan makna, retorika, dan arahan baru. Ini pada gilirannya dikomunikasikan melalui media yang dikendalikan negara untuk merayakan UEA sebagai komunitas politik yang telah membuat langkah besar bagi rakyatnya. Mereka juga memberikan legitimasi kepada para syekh sebagai pemimpin nasional yang membimbing rakyatnya dengan cara yang terpuji. Kontribusi besar-besaran dari kebangkitan warisan syekh bertujuan untuk mempengaruhi persepsi politik warga negara tentang negara, dan juga untuk mempromosikan rasa identitas nasional mereka.

\section{Problema Pemenuhan Kebutuhan : Air Bersih (Consumable Mineral Water)}

Geografis sebagai faktor utama dari ekosistem bumi menghasilkan kekayaan alam yang beragam. Timur tengah yang bersanding dengan negara-negara bagian barat berlomba dalam pemanfaatan yang optimal dalam mengolah sumber daya yang disediakan bumi. Hal ini dirasakan dan dialami oleh negara maju di Timur Tengah sekalipun yaitu Emirat Arab sendiri. Emirat yang didominasi padang pasir yang gersang dan kering mendesak rakyatnya untuk berpikir lebih kompleks agar dapat mempertahankan dan menjaga keberlangsungan hidup terutama air bersih.

Air bersih adalah sumber kehidupan mutlak yang dibutuhkan manusia. Ketersediaan air bersih yang dapat dikonsumsi tidak sebanyak air laut yang menguasai planet bumi. Teknologi dan kekayaan harta sebuah negara mejadi tolak ukur pendukung dalam meraih tujuan sebuah negara khususnya Emirat Arab dalam konteks ini. Pemanfaatan alam yang dimanipulasi agar dapat memenuhi kebutuhan air bersih menjadi ide mengatasi problema ini yang diterapkan oleh Uni Emirat Arab.

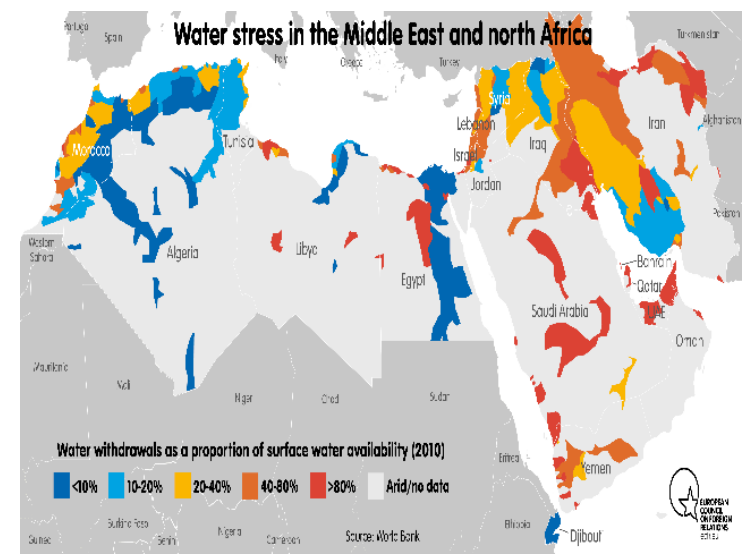

Gambar 1. Kelangkaan Air di Timur Tengah dan Afrika Utara (Sumber : World Bank.2010)

Pada Gambar 1 menjelaskan kondisi geografis kelangkaan air tanah yang terjadi di Timur Tengah dan Afrika Utara pada dekade terakhir ini. Kelangkaan air pernah menimbulkan gesekan politik di Benua Afrika, khususnya Mesir dan beberapa negara tetangganya terkait kepemilikan sungai Nil. Hal ini menunjukkan bahwa air adalah kebutuhan mutlak yang sangat sensitif sehingga ketergantungannya harus dapat dikelola dengan baik. Uni Emirat Arab merupakan negara yang termasuk ke dalam tingkat kelangkaan yang sangat tinggi yaitu lebih dari $80 \%$.

Emirat Arab yang kaya akan kekayaan alamnya dan harta yang melimpah disertai dengan kemajuan pola pikir dan teknologi, membuat mereka 
berpikir lebih kompleks dan mendalam melebihi negara yang lain dengan kekayaan akan air bersihnya. Skema dan perencanaan telah dirancang pada 2-3 dekade terakhir untuk mengatasi permasalahan yang dihadapi. Keberhasilan membuat pulau dari hasil membeli pasir/tanah dari negara lain membuat mereka tidak pernah berhenti berjuang untuk mengatasi kasus ini. Terdapat dua metode yang diterapkan oleh Emirat Arab untuk menangani permasalahan ini yaitu desalinasi air laut dan penyemaian garam pada awan yang kemudian menimbulkan hujan dan dilakukan penampungan di danau buatan sehingga dapat memenuhi kebutuhan air bersih di Emirat Arab.

\subsection{Desalinasi Air Laut}

Menurut Asosiasi Desalinasi Internasional dalam laporan tahunannya yang dipublikasikan dengan nama $\mathrm{OK}$ BUROS dengan judul karya ilmiah The $A B C$ s of Desalting, desalinasi adalah suatu proses yang memisahkan kadar garam dari air tawar. Proses ini dapat dilakukan daiam beberapa cara, tapi tujuannya adalah sama, yaitu mendapatkan air bersih dari air laut atau air payau. Kualitas air ini ditentukan oleh total dissolve solid (TPS) yang mempunyai satuan part per million (ppm) yang dinyatakan dengan makin kecill ppm, maka makin baik kualitas air yang dihasiikan. Proses ini menghasilkan air bersih (distilat) dengan kadar garam sangat rendah, sekitar $10 \mathrm{ppm}$.

Teknologi desalinasi dimulai di UEA pada tahun 1976, ketika pabrik pertama didirikan di Abu Dhabi dengan kapasitas 66.000 galon / hari. Berdirinya instalasi desalinasi sejak saat itu menunjukkan bahwa kelangkaan air merupakan masalah lama dan tingkat keparahan masalah ini semakin meningkat setiap tahunnya. Seiring dengan berjalannya waktu, kebutuhan air untuk domestik, pertanian dan industri semakin meningkat, sehingga pabrik desalinasi baru sedang dibangun di negara tersebut. Sebanyak 36 instalasi desalinasi telah dibangun di UEA pada akhir tahun 2006. Selain itu, terdapat 10 stasiun desalinasi utama milik FEWA dan beroperasi di bagian utara dan timur negara tersebut. Juga, ada 8, 5 dan 12 stasiun desalinasi utama di Abu Dhabi, Dubai dan Sharjah. Selain itu, terdapat 2 tanaman yang melakukan desalinasi air tanah di Umm Al Quwain (berdasarkan Water Desalination Report of UAE halaman 1-4, 2011)

Produksi air desalinasi meningkat dari waktu ke waktu untuk menyediakan air dalam jumlah yang cukup untuk berbagai kegiatan. Sejak 2000, UEA terus bergantung pada air tanah dan air olahan selain air desalinasi untuk memenuhi permintaan air yang meningkat untuk berbagai tujuan. Total produksi air desalinasi di UEA adalah 134412,8 juta galon pada tahun 2000 dan meningkat menjadi 277942,14 juta galon pada tahun 2006. Peningkatan produksi air desalinasi diamati di semua Emirat Arab. Produksi desalinasi lebih tinggi di Abu Dhabi dan Dubai karena perkembangan ekonomi baik di Emirat maupun imigran yang cepat ke Abu Dhabi dan Dubai yang mencari stabilitas politik.

Ketergantungan air desalinasi untuk semua emirat lebih tinggi daripada air tanah dan persentase ketergantungan meningkat secara signifikan karena kekurangan air tanah. Produksi air oleh ADWEA terutama bergantung pada desalinasi dan ketergantungannya meningkat dari $85,95 \%$ pada tahun 2000 menjadi $99,73 \%$ pada tahun 2006. Selain itu, produksi air DEWA terutama air desalinasi dengan persentase ketergantungan $95,7 \%$ pada tahun 2006 dibandingkan dengan $93,73 \%$ pada tahun 2000 Namun, ketergantungan air desalinasi SEWA dan FEWA pada tahun 2000 adalah $52,78 \%$ dan $35,02 \%$ dan meningkat masing-masing menjadi $66,22 \%$ dan 62,11\% pada tahun 2006, jelas terlihat bahwa Emirat Timur dan Utara negara ini bergantung pada air tanah dan air desalinasi, sedangkan Abu Dhabi dan Dubai mengandalkan air desalinasi. Produksi airtanah di Emirat Timur dan Utara relatif tinggi karena kedekatannya dengan daerah imbuhan, tetapi ketergantungan terhadap air tanah di daerah tersebut akan berkurang seiring dengan berjalannya waktu dan bergantung 
pada air desalinasi akan meningkat untuk menutupi defisit air tanah melihat penduduk negara yang meningkat pesat.

\subsection{Manipulasi Hujan dengan Penyemaian Garam pada Awan}

UEA telah melakukan operasi penyemaian awan sejak lebih dari satu dekade untuk meningkatkan curah hujan di negara tersebut dan menurunkan suhu. Program cloud-seeding-nya dimulai pada 1990-an. Pada awal 2001, program ini bekerja sama dengan organisasi terkenal seperti Pusat Penelitian Atmosfer Nasional (NCAR) di Colorado, AS, serta Universitas Witwatersrand di Afrika Selatan dan Badan Antariksa AS, NASA. Pada tahun 2005, UEA meluncurkan Penghargaan UEA untuk Keunggulan dalam Memajukan Sains dan Praktik Modifikasi Cuaca bekerja sama dengan Organisasi Meteorologi Dunia (WMO). Pada Januari 2015, menjadi Program Penelitian UEA untuk Ilmu Peningkatan Hujan (UAEREP). Ini diprakarsai oleh Kementerian Urusan Kepresidenan Uni Emirat Arab dan diawasi oleh Pusat Meteorologi \& Seismologi Nasional (NCMS) UEA yang berbasis di Abu Dhabi. UEA sekarang memiliki lebih dari 60 stasiun cuaca berjaringan di UEA, jaringan radar cuaca, dan enam pesawat untuk operasi penyemaian awan. Operasi peningkatan hujan difokuskan di daerah pegunungan di timur laut negara itu, tempat awan kumulus berkumpul di musim panas. Yang penting, tidak ada bahan kimia berbahaya yang digunakan dalam operasi penyemaian awan UEA; pesawat khusus kami hanya menggunakan garam alami, dan tidak ada bahan kimia berbahaya. Pada 2018, 46,5 mm curah hujan tercatat di UEA, menurut National Center of Meteorology (NCM), meskipun negara tersebut telah melakukan 184 operasi penyemaian awan. Pada 2019, jumlahnya meningkat menjadi $101,1 \mathrm{~mm}$ dengan 247 operasi dilakukan. Dengan jumlah air yang lebih besar yang tercatat di negara ini, lebih banyak air yang dapat ditahan daripada menguap karena suhu turun sedikit dan curah hujan lebih sering terjadi (berdasarkan UAE Research Program for Rain Enhancement Science).
Seperti halnya metode baru yang ditemukan, ada banyak kelemahan cloud seeding yang mungkin memengaruhi penggunaan dan efisiensinya. Perlu diketahui bahwa penyemaian awan melibatkan penggunaan bahan kimia di udara. Ini berarti bahan kimia berbahaya dapat terlontar ke udara. Bahan kimia yang digunakan dalam penyemaian awan berpotensi merusak lingkungan, terutama penyemaian awan tanaman dimaksudkan untuk melindungi. Tidak ada studi substansial yang dilakukan tentang implikasi yodium perak terhadap lingkungan. Yodium perak dapat menyebabkan "yodium", sejenis keracunan yodium di mana pasien mengalami sakit kepala, ruam kulit, anemia, dan diare, dan lain-lain. Telah ditemukan pula bahwa hal itu sangat beracun bagi ikan, ternak, dan manusia. Namun, efek lengkap dari penyemaian awan pada lingkungan secara keseluruhan belum sepenuhnya diketahui, tetapi mungkin akan berubah di masa depan karena lebih banyak penelitian dilakukan dan diselesaikan, hal ini disampaikan oleh N. Regoli (2015) dalam artikel penelitiannya yang berjudul 12 Important Pros and Cons of Cloud Seeding.

Efisiensi penyemaian awan belum terbukti hingga saat ini. Telah ditemukan bahwa penyemaian awan banyak digunakan pada awan yang sudah menunjukkan tanda-tanda hujan. Jadi, kesuksesan terbaik terjadi saat konidisi awan gelap dan hampir siap turun hujan. Menurut S. Malik, H. Bano, Rather, dan S. Ahmad (2018), dalam jurnal ilmiahnya yang berjudul Cloud Seeding; Its Prospects and Concerns in the Modern World, apabila penyemaian awan dicoba pada awan putih normal, peluang mendapatkan hasil positif adalah 50/50. Selain itu, awan yang telah disemai sebenarnya dapat bergerak ke lokasi lain dan tidak menyebabkan curah hujan di lokasi yang dimaksudkan. Oleh karena itu, dapat diperdebatkan apakah penyemaian awan benar-benar efektif dalam menghasilkan hujan atau tidak.

Cloud seeding dapat menyebabkan kejadian yang tidak diinginkan jika tidak 
diatur atau dikontrol dengan benar. Ketika bahan kimia dilepaskan ke awan, tidak ada kendali atas jenis cuaca apa yang akan terbentuk. Di banyak daerah, kemungkinan curah hujan terlalu tinggi yang dapat menyebabkan banjir. Tempat-tempat yang secara alami tidak mendapat banyak hujan atau tidak ada hujan sama sekali biasanya tidak memiliki infrastruktur untuk menangani curah hujan yang begitu banyak. Dengan penyemaian awan, area ini dapat menjadi banjir dengan cepat, menyebabkan lebih banyak kerusakan daripada kebaikan. Beberapa orang bahkan takut bahwa, alih-alih menyelesaikan masalah kekurangan air, penyemaian awan justru akan memperburuk masalah, hal ini pula dikemukakan oleh N. Regoli dalam artikel penelitian yang sama dengan sebelumnya.

\section{Kesimpulan}

Penyemaian garam di atmosfer beserta desalinasi/filtrasi air laut menjadi air siap konsumsi merupakan aksi yang dilakukan Emirat Arab untuk memenuhi kebutuhan rakyatnya. Perubahan ekosistem alam yang mulanya gersang menjadi tandus dan hijau merupakan aksi yang hampir mustahil tetapi berhasil dilakukan dan diterapkan oleh negara maju di Timur Tengah ini. Segala daya dan upaya dilakukan agar dapat memenuhi kebutuhan manusia sehingga mengabaikan dampak yang berpotensi akan timbul terhadap ekosistem lingkungan dan bahkan terhadap manusia.

Kondisi melakukan aktivitas bertentangan dengan ekosistem alam tentunya memberikan dampak yang mungkin akan dirasakan di kemudian hari. Senyawa kimia yang dipaksakan untuk memanipulasi kondisi curah hujan dapat menimbulkan curah hujan yang tidak terkendali dan tidak alami sehingga berlebihan dan menyebabkan kebanjiran yang dialami beberapa tahun belakangan ini di UEA dan beberapa negara Timur Tengah lainnya akibat kegiatan tersebut. Lalu timbul pertanyaan mengenai hal tersebut apakah pengubahan bentuk dan memanipulasi alam yang seharusnya seperti sedia kala pada ekosistem ini akan berdampak atau menguntungkan khalayak orang banyak.

\section{Daftar Pustaka}

P. D. Tortell, Ed., Earth 2020: An Insider's Guide to a Rapidly Changing Planet. Open Book Publishers. 2020.

Creswell, John W. 2009. Research Design: Qualitative, Quantitative, and Mixed Methods Approaches. Thousand Oaks: Sage Publications.

Alan Bryman. 2012. "Social Research Methods, 4th Edition". Oxford University Press. New York.

Lexy J., Moleong. 1996. Metodologi Penelitian Kualitatif. PT Remaja Rosdakarya: Bandung

IUCN. "Illegal Activities Threaten Natural World Heritage, Pushing the Vaquita to the Brink and Depleting Forests." IUCN, 3 July 2017, www.iucn.org/news/iucn41whc/201706/illegal-activitiesthreaten-natural-world-heritagepushing-vaquita-brink-anddepleting-forests-\%E2\%80\%93iucn. Diakses 22 Desember 2020.

Bonner, H. 1959. Social Psychology. American Book Company. USA.

Satriya, Bambang. 2009. Paradigma Baru Pendidikan Kewarganegaraan di Perguruan Tinggi. Nirmana Media: Jakarta.

Abo Khashaba, Saif. 2017. Economic Importance of Niobium and Tantalum. University in Kafr elSheikh, Egypt.

Ventura, Luca. "Poorest Countries in the World 2020." Global Finance Magazine, 22 July 2020, https://www.gfmag.com/globaldata/economic-data/the-poorest- 
countries-in-the-world. Diakses 21 Desember 2020.

Ventura, Luca. "Poorest Countries in the World 2020." Global Finance Magazine, 22 July 2020, https://www.gfmag.com/globaldata/economic-data/the-poorestcountries-in-the-world. Diakses 21 Desember 2020.

Kazim, M. 2007. Assessments of Primary Energy Consumption and Its Environmental Consequences in The United Arab Emirates. Renew Sust Energy Rev 426-446.

Khalaf, Sulayman. 2000. Poetics and Politics of Newly Invented Traditions in the Gulf: Camel Racing in the United Arab Emirates. Univerity of Pittsburgh. USA.

BUROS, O.K..The ABCs of Desalting, International Desalination Association

Water Desalination Report of UAE halaman 1-4 . 2011.

Rain Enhancement. United Arab Emirates Research Program for Rain Enhancement Science. [Online].http://www.uaerep.ae/en/a pp/16\#. Diakses 28 Desember 2020.

S. Malik, H. Bano, R. A. Rather and S. Ahmad. 2018. Cloud Seeding; Its Prospects and Concerns in the Modern World. Int. J. Pure App, vol. 6 (5), no. 2320 - 7051, pp. 791-796.

N. Regoli, " 12 Important Pros and Cons of Cloud Seeding," Connect Us, 23 August 2015. [Online]. https://connectusfund.org/12important-pros-and-cons-of-cloudseeding. Diakses 28 Desember 2020. 